\title{
Zonula occludens and nasal epithelial barrier integrity in allergic rhinitis
}

\author{
Che Othman Siti Sarah ${ }^{1}$, Norasnieda Md. Shukri ${ }^{2}$, Noor Suryani Mohd Ashari ${ }^{1}$, Kah Keng Wong ${ }^{\text {Corresp. } 1}$ \\ ${ }^{1}$ Department of Immunology, School of Medical Sciences, Universiti Sains Malaysia, Kubang Kerian, Kelantan, Malaysia \\ 2 Department of Otorhinolaryngology, School of Medical Sciences, Universiti Sains Malaysia, Kubang Kerian, Kelantan, Malaysia \\ Corresponding Author: Kah Keng Wong \\ Email address: kahkeng@usm.my
}

Allergic rhinitis (AR) is a common disease affecting 400 million of the population worldwide. Nasal epithelial cells form a barrier against the invasion of environmental pathogens. These nasal epithelial cells are connected together by tight junction (TJ) proteins including zonula occludens-1 (ZO-1), ZO-2 and ZO-3. Impairment of ZO proteins are observed in AR patients whereby dysfunction of ZOs allows allergens to pass the nasal passage into the subepithelium causing AR development. In this review, we discuss on ZO proteins and their impairment leading to $A R$, regulation of their expression by Th1 cytokines (i.e. IL-2, TNF- $\alpha$ and IFN- $\gamma$ ), Th2 cytokines (i.e. IL-4 and IL-13) and histone deacetylases (i.e. HDAC1 and HDAC2). These findings are pivotal for future developments of targeted therapies by restoring ZO protein expression and improving nasal epithelial barrier integrity in AR patients. 


\section{Zonula occludens and nasal epithelial barrier integrity 2 in allergic rhinitis}

4 Che Othman Siti Sarah ${ }^{1}$, Norasnieda Md. Shukri², Noor Suryani Mohd Ashari ${ }^{1}$, Kah Keng

5 Wong $^{1}$

${ }^{1}$ Department of Immunology, School of Medical Sciences, Universiti Sains Malaysia, 16150

8 Kubang Kerian, Kelantan, Malaysia.

9 2Department of Otorhinolaryngology, School of Medical Sciences, Universiti Sains Malaysia, 1016150 Kubang Kerian, Kelantan, Malaysia.

Corresponding author:

13 Assoc. Prof. Dr. Kah Keng Wong (BSc, Mal; DPhil, Oxon)

14 Department of Immunology,

15 School of Medical Sciences,

16 Universiti Sains Malaysia,

1716150 Kubang Kerian, Kelantan, Malaysia

18 Tel: +609 7676229; Fax: +609 7653370

19

E-mail: kahkeng@usm.my 
35

36

37

38

39

40

41

42

\section{ABSTRACT}

Allergic rhinitis (AR) is a common disease affecting 400 million of the population worldwide. Nasal epithelial cells form a barrier against the invasion of environmental pathogens. These nasal epithelial cells are connected together by tight junction (TJ) proteins including zonula occludens1 (ZO-1), ZO-2 and ZO-3. Impairment of ZO proteins are observed in AR patients whereby dysfunction of ZOs allows allergens to pass the nasal passage into the subepithelium causing AR development. In this review, we discuss on $\mathrm{ZO}$ proteins and their impairment leading to AR, regulation of their expression by Th1 cytokines (i.e. IL-2, TNF- $\alpha$ and IFN- $\gamma$ ), Th2 cytokines (i.e. IL-4 and IL-13) and histone deacetylases (i.e. HDAC1 and HDAC2). These findings are pivotal for future developments of targeted therapies by restoring $\mathrm{ZO}$ protein expression and improving nasal epithelial barrier integrity in AR patients.

Subjects Allergy and Clinical Immunology, Immunology, Otorhinolaryngology

\section{INTRODUCTION}

Tight junction (TJ) proteins are required to form the nasal epithelial barrier and maintain its integrity. Breakdown of TJ function or expression deregulation is associated with derailed nasal epithelial barrier, leading to infiltration by allergens and subsequent development of allergic rhinitis (AR) (Fukuoka \& Yoshimoto, 2018; Steelant et al., 2016). Moreover, growing evidence has implicated regulation of the nasal epithelial barrier integrity by histone deacetylases (HDACs), Th1 and Th2 cytokines in AR. Thus, an overall assessment and compilation of this accumulating evidence is desirable. In this review, we present and discuss the mechanisms leading to breakdown of TJs specifically on zonula occludens (ZOs), a group of important TJ proteins, as well as regulation of their expression by HDACs, Th1 and Th2 cytokines that would be informative for clinicians and researchers alike in this field.

\section{SURVEY METHODOLOGY}

This review focuses on ZOs and their regulators i.e. HDACs, Th1 and Th2 cytokines in AR research. All articles were searched and screened by two investigators (COSS, KKW) using the electronic databases PubMed and Google Scholar. References described in this review were obtained from the databases up to year 2019. The following keywords were used: "allergic rhinitis", “AR”, “nasal epithelial barrier integrity”, “zonula occludens", “ZO”, "histone deacetylases", "HDACs", "Th1" and "Th2".

\section{ALLERGIC RHINITIS (AR)}

Allergy is a hypersensitivity reaction that occurs when an individual is sensitized by allergens such as grass, tree pollen, house dust mites (HDMs), foods, insect venoms or medicines (Azid et al., 2019; Sani et al., 2019; Tanno et al., 2016). AR is a global health issue affecting 
approximately $10-25 \%$ of the population worldwide (Elango, 2005). AR can be characterized by events of sneezing, rhinorrhea, nasal obstruction, nasal itching and postnasal drip. It is also associated with itching of the eyes, ears and throat (Elango, 2005; Pang et al., 2017).

Onset of AR consists of two phases of reaction where the first phase involves allergen infiltration that induces the production of immunoglobulin E (IgE) and triggers the humoral immune response mediated by mast cells. The second phase is a clinical phase where the patients present with symptoms of AR as a response to subsequent antigen exposure. This involves the release of mediators such as multiple cytokines and chemokines. Nasal symptoms can be observed within minutes due to the release of neuroactive and vasoactive agents including histamine, cysteinyl leukotrienes and prostaglandin $\mathrm{D}_{2}$ (Wheatley \& Togias, 2015). The mucosa is rendered more reactive to allergens and nasal symptoms can persist for days after exposure to allergens (Sarin et al., 2006; Wheatley \& Togias, 2015).

$\mathrm{AR}$ is also defined immunologically as an IgE-mediated inflammation reaction in the nasal airways. This is primarily due to exposure to environmental pathogens, allergens or any foreign agents that induce an inflammation reaction (Bayrak Degirmenci et al., 2018). These allergens contain proteases that contribute to the disruption of the airway epithelial barrier (Runswick et al., 2007; Schleimer \& Berdnikovs, 2017; Wan et al., 1999). The interaction between IgE and dendritic cells (DCs) increases allergen uptake and its subsequent processing and presentation to naive T cells (Sin \& Togias, 2011). Hence, higher allergen infiltration into the nasal airway increases the production of IgE in the blood. Perennial AR patients present with higher total $\operatorname{IgE}$ levels (Lee et al., 2016; Shirasaki et al., 2011).

\section{NASAL EPITHELIAL BARRIER INTEGRITY IN AR}

The nasal epithelial barrier plays an important role in sealing the nasal passage and underlying tissues from foreign pathogens by connecting the epithelial cells to each other (London \& Ramanathan, 2017; Steelant et al., 2016). Any intrusion from foreign particles can stimulate the production of antimicrobial host defence molecules, pro-inflammatory cytokines and chemokines by nasal epithelial cells through the activation of recognition receptors. In addition, $\mathrm{T}$ cells are also recruited to epithelial cells to enhance adaptive immunity.

Dysfunction of these TJ barriers can increase exposure of nasal tissues to environmental antigens. It can lead to the infusion of inflammatory cells into the lumen which contributes to tissue damage or inflammation (Soyka et al., 2012). The disruption of the mucosal epithelial barrier has also been observed in AR animal models (Zhang et al., 2016).

The nasal epithelial barrier is primarily formed by cell-to-cell TJs which consist of integral membrane proteins such as claudins, occludin, junctional adhesion molecules (JAMs), as well as 
112 scaffold adaptor proteins consisting of ZO-1, ZO-2 and ZO-3 (Beutel et al., 2019; London \& 113 Ramanathan, 2017). These proteins form the intercellular connection between the cells that 114 regulate the passage of foreign pathogens (Steelant et al., 2016). These proteins connect together 115 to form a complex structure that protects the epithelial barrier from inhaled pathogens (Figure 1).

116

\section{ZONULA OCCLUDENS (ZO) PROTEINS}

118

119

120

121

122

123

124

125

126

127

128

129

130

131

132

133

134

135

136

137

138

139

140

141

142

143

144

145

146

147

148

149

$\mathrm{ZO}$ proteins are a group of key proteins associated with TJ molecules that connect transmembrane proteins to the actin cytoskeleton (Steelant et al., 2016). ZO proteins form an anchor directly to the underlying cytoskeleton with other $\mathrm{T}$

J proteins including occludin, claudin, JAMs and tricellulin (Bauer et al., 2010; Furuse et al., 1994). ZO proteins belong to the family of membrane-associated guanylate kinase (MAGUK)like proteins. MAGUKs are scaffolding proteins that form and maintain multimolecular complexes at distinct subcellular sites such as the cytoplasmic surface of the plasma membrane (Bauer et al., 2010).

ZO-1, ZO-2 and ZO-3 form a belt-like region at the outer end of intercellular space between the epithelial cells that separates the apical from the lateral plasma membrane. The proteins also play vital roles in regulating the passage of ions and molecules through the membrane (GonzalezMariscal et al., 2000). ZO proteins consist of a multidomain structure including SRC homology 3 (SH3), guanylate kinase-like (GUK) and multiple PDZ domains (Anderson, 1996).

ZO-1 and ZO-2 have been detected in human nasal mucosa where ZO-1 is found in the uppermost layer of epithelium (Kojima et al., 2013). ZO-1 protein contains an N-terminal PDZ domain that can recognize specific C-terminal or other peptide motifs to assemble with other $\mathrm{TJ}$ molecules such as claudins to form a TJ barrier at gaps between epithelial cells (Heinemann \& Schuetz, 2019; Herve et al., 2014; Umeda et al., 2006). The TJ barrier controls the diffusion of molecules by acting as semipermeable diffusion barriers through the paracellular pathway. It has been reported that transmembrane proteins such as claudin and occludin are essential for the regulation of paracellular permeability (Balda \& Matter, 2000; Lee, 2015; Roehlen et al., 2020). ZO-1 is also responsible for the regulation of paracellular permeability (i.e. permeability for the passage of molecules between adjacent epithelial cells) via TJ complexes as it binds directly to transmembrane proteins (Balda \& Matter, 2000; Lee, 2015; Roehlen et al., 2020). Loss of ZO-1 can retard the formation of the TJ complexes, and further breakdown of ZO-1 may result in severe disruption of the paracellular barrier in epithelial cells (Roehlen et al., 2020). Hence, ZO1 plays important roles in maintaining the epithelial barrier by connecting TJ molecules to seal the epithelial cells from infiltration of environmental allergens.

\section{Disruption of ZO proteins in AR}


150 The disruption of $\mathrm{ZO}$ proteins affects the interaction of TJ molecules, allowing the passage of

151

152

153

154

155

156

157

158

159

160

161

162

163

164

165

166

167

168

169

170

171

172

173

174

175

176

177

178

179

180

181

182

183

184

185

186

187

188

189

allergens into the host. Decreased expression of ZO-1 in AR patients has been reported by gene expression studies (Lee et al., 2016; London \& Ramanathan, 2017). A study by Steelant and colleagues showed decreased levels of ZO-1 through immunofluorescent staining on AR biopsy specimens (Steelant et al., 2016). Furthermore, nasal epithelial cells isolated from inferior turbinate of HDM-induced AR patients demonstrated reduced ZO-1 mRNA expression (Steelant et al., 2018). Likewise, the expression of ZO-1 in asthma and chronic rhinosinusitis patients was also decreased compared with healthy controls (de Boer et al., 2008; Soyka et al., 2012).

Immunofluorescence analysis of RPMI 2650, a human nasal epithelial cell line, showed a decreased of ZO-1 expression after being exposed to diesel exhaust particles (Fukuoka et al., 2016). Transepithelial electric resistance (TER) measurement, a procedure that assessed the integrity of TJ in cell culture of epithelial monolayers, of the RPMI 2650 was reduced in the study, and the decreased ZO-1 expression was associated with severity of AR (Fukuoka et al., 2016). Moreover, HDM cysteine proteinase antigen from Dermatophagoids pteryonysinus caused the mislocalization of ZO-1 from TJ (Wan et al., 1999). Hence, patients with AR demonstrate lower integrity of nasal epithelial barrier that is associated with decreased expression or disruption of ZO-1 protein.

Accumulating evidence has shown that reduced expression of ZO-1 or ZO-2 occurs in patients with chronic rhinosinusitis (CRS) without nasal polyps (Soyka et al., 2012) or eosinophilic esophagitis (EoE) (Katzka et al., 2014), respectively. CRS is characterized by mucosal inflammation involving both the nasal cavity and paranasal sinuses (Soyka et al., 2012), while EoE represents inflammation of the oesophagus when food antigens interact with oesophageal mucosa (Katzka et al., 2014). Both CRS and EoE are caused by the penetration of antigens through the gap between nasal epithelial cells (Katzka et al., 2014; Soyka et al., 2012). The expression of ZOs in these allergic diseases in both patients and animal models are summarized in Table 1.

\section{HISTONE DEACETYLASES (HDACs) IN AR}

HDACs are enzymes responsible for removing acetyl group from lysine residues of target proteins. HDACs prevent gene transcription by allowing DNA to be wrapped by histones (Jiang et al., 2015). HDACs also promote the condensation of chromation (Shakespear et al., 2011). HDACs have been implicated in several inflammatory and allergic conditions including AR (Barnes, 2013; Sweet et al., 2012; Vendetti \& Rudin, 2013). Upregulation of HDAC activity occurs in nasal epithelial cells of AR patients (Steelant et al., 2019).

It has been shown that expression of TJs can be increased by inhibiting the activity of HDAC1 and simultaneously decreasing the defect of epithelial barriers (Wawrzyniak et al., 2017). In animal models, HDAC1 protein levels in rats AR model were higher than naive rats (Jiang et al.,

Peer) reviewing PDF | (2020:01:45164:2:0:NEW 29 Jul 2020) 
190

191

192

193

194

195

196

197

198

199

200

201

202

203

204

205

206

207

208

209

210

211

212

213

214

215

216

217

218

219

220

221

222

223

224

225

226

227

228

229

2015). Immunohistochemical results also demonstrated higher expression of HDAC1 protein in nasal epithelium of patients with sinusitis and nasal polyps contributing to the disruption of TJs (Kaneko et al., 2017). Furthermore, HDAC1 could supress the activity of TWIK-related potassium channel-1 (Trek-1), and Trek-1 is pivotal in the maintenance of epithelial cell barrier function (Bittner et al., 2013). Higher mRNA expression of HDACl together with lower mRNA expression of Trek-1 was found in nasal epithelial cells from patients with AR compared with healthy subjects (Wang et al., 2015).

ZO-1 expression was previously shown to be decreased in the presence of HDAC1.Lower levels of ZO-1 mRNA expression were observed in AML-12 murine hepatocyte cells that overexpressed HDAC1 (Lei et al., 2010). Studies on epithelial-mesenchymal transition (EMT), an oncogenic process that induces epithelial cells to transform into anchorage-independent mesenchyme-like cells for increased metastatic capabilities of cancer cells, also showed an association with HDAC1 and ZO-1 (Zhou et al., 2015). ZO-1 is involved in EMT where loss of ZO-1 expression can induce invasion of cancer cells. Higher HDAC1 mRNA and protein expression levels were found in hepatocellular carcinoma (HCC) cell lines (HepG2, Hep3B, Huh7, PLC/PRF/5, SK-Hep-1) compared with normal human epithelial cell line (THLE-3) (Zhou et al., 2015). Inhibition of HDAC1 in these HCC cells showed an increase of ZO-1 mRNA and protein expression, leading to decreased invasion capabilities of HCC cells (Zhou et al., 2015). Thus, ZO-1 expression can be inhibited by HDAC1 leading to breakdown of epithelial cells' anchorage, and it remains unknown if similar effects might also occur in nasal epithelial cells.

In contrast with HDAC1, evidence has shown that HDAC2 expression is required to prevent breakdown of nasal epithelial barrier integrity in AR. Decreased levels of HDAC2 were observed in patients with asthma and asthmatic smoking patients, as in patients with chronic obstructive pulmonary disease (Bhavsar et al., 2008). Higher levels of HDAC2 can restore steroid sensitivity in asthmatic patients (Bhavsar et al., 2008), and nasal scrape samples of patients with persistent AR showed weak expression of HDAC2 (Sankaran et al., 2014). Moreover, deficiency of HDAC2 in intestinal epithelial cells (IEC) of mice was associated with chronic basal inflammation (Turgeon et al., 2013). Deletion of HDAC2 from IEC displayed an increased permeability to fluorescein isothiocyanate-dextran 4kDa (FD4; a fluorochrome for investigation of cell permeability) by assessing the intensity of fluorescence in the mice blood (Turgeon et al., 2013), and increased penetration by FD4 indicated increased leakiness that may be due to disruption of epithelial barrier.

However, downregulation of HDAC2 with the treatment of Trichostation-A (TSA), an HDAC inhibitor (HDACi), increased the expression of $Z O-1 \mathrm{mRNA}$ in fetal human lens epithelial cells (Ganatra et al., 2018). TSA treatment in this study decreased the association between HDAC2 with the promoter region of $\mathrm{ZO}-1$ as demonstrated by chromatin immunoprecipitation assay (Ganatra et al., 2018). The effect of HDAC2 inhibitor CAY10683 was investigated on the 
230

231

232

233

234

235

236

237

238

239

240

241

242

243

244

245

246

247

248

249

250

251

252

253

254

255

256

257

258

259

260

261

262

263

264

265

266

267

268

expression on ZO-1 at the intestinal mucosal barrier of lipopolysaccharide (LPS)-stimulated NCM460 cells (a normal human colon mucosal epithelial cell line) (Wang et al., 2018). LPS was used to induce damage to the mucosal barrier of NCM460 cells. The NCM460 cells treated with the HDAC2 inhibitor (CAY10683) increased mRNA and protein levels of ZO-1 (Wang et al., 2018). Collectively, this suggests that HDAC2 plays differential roles in the increase or reduction of epithelial barrier integrity depending on the site of the human epithelial cells. HDAC2 prevents the breakdown of nasal epithelial barrier but it may promote the opposite effect in human lens or colon mucosal epithelial cells via downregulation of ZO-1 expression.

Inhibiting HDAC activities with HDACi (JNJ-26481585) may be able to restore the structure of ZO molecules in nasal epithelial cells (Steelant et al., 2019). In the same study, immunofluorescent staining showed that ZO-1 expression was significantly weaker in AR patients compared with healthy controls, and further treatment with JNJ-26481585 increased the expression of ZO-1 protein.

The HDACi sodium butyrate $(\mathrm{SoB})$ is a short chain fatty-acid produced by the microbial fermentation of dietary fibre in colonic lumen (Bordin et al., 2004). The Rat-1 fibroblasts cell line expresses ZO-1 and ZO-2 proteins (Bordin et al., 2004). When the cells lysates were cultured in the presence of SoB, densitometric analysis of immunoblots showed that ZO-1 and ZO-2 levels were upregulated (Bordin et al., 2004). Collectively, HDAC1 and HDAC2 suppress the expression of $\mathrm{ZO}$ proteins leading to breakdown of epithelial cells barrier integrity as demonstrated by these studies either in AR or non-AR epithelial cells.

\section{TH1 CYTOKINES IN AR}

Cytokines play an important role in mediating allergic inflammation. The roles of Th2 cytokines in AR have been well-documented (Steelant et al., 2016; Sun et al., 2020; Zhao et al., 2017). Imbalance of Th1 and Th2 cytokines appears to be involved in the AR inflammatory pathway (Zhao et al., 2017). However, there is a lack of review on Th1 cytokines and their roles in the breakdown of nasal epithelial barrier integrity. Moreover, dysfunctional Th1 responses have been proposed to be responsible for the exaggerated $\mathrm{Th} 2$ responses that occur in AR patients (Eifan \& Durham, 2016). Th1 cells produce IL-2, IFN- $\gamma$ and TNF- $\alpha$ in response to allergic inflammation (Ackaert et al., 2014). Th1 cytokines can cause disruption of TJ molecules including ZO proteins in nasal epithelial barrier, leading to allergic inflammation.

Th1 response is characterized by IFN- $\gamma$ production which stimulates bactericidal activities of macrophages and boosts immunity against intracellular pathogens and virus infection (Marshall et al., 2018). IFN- $\gamma$ plays a key role in bridging the innate and adaptive immune systems (Bayrak Degirmenci et al., 2018). It is also essential in the regulation of local leukocyte-endothelial interaction (Akkoc et al., 2008). 
IFN- $\gamma$ increases the permeability of primary bronchial epithelial cells and T84 colonic epithelial

271

272

273

274

275

276

277

278

279

280

281

282

283

284

285

286

287

288

289

290

291

292

293

294

295

296

297

298

299

300

301

302

303

304

305

306

307

308 cells by disassembling TJ structures (Bruewer et al., 2005). In order to observe the expression of ZO-2 in CRS patients, human epithelial cells were treated on air-liquid interface (ALI) culture with IFN- $\gamma$. The results showed that opening of TJs between the neighbouring cells occurred in patients compared with healthy controls (Soyka et al., 2012). However, no significant decrease of ZO-1 expression in AR patients was observed when the epithelial cells were treated with IFN- $\gamma$ and TNF- $\alpha$ cytokines (Lee et al., 2016). Additionally, cultured primary nasal epithelial cells in ALI stimulated with TNF- $\alpha$ and IFN- $\gamma$ showed a decrease of epithelial barrier integrity in vitro (Steelant et al., 2018).

Furthermore, expression of ZO-1 protein in primary airway cells from cystic fibrosis patients was reduced in the presence of IFN- $\gamma$ and TNF- $\alpha$ cytokines (Coyne et al., 2002). Prolonged exposure of IFN- $\gamma$ and TNF- $\alpha$ to the cell culture led to a significant damage to ZO-1 molecules (Coyne et al., 2002). This damage caused an increase of cell permeability to external solutes and a decrease in transepithelial resistance. Further investigation of wild type BALB/c mice endonasally instilled with IFN- $\gamma$ and TNF- $\alpha$ increased the FD4 mucosal barrier permeability associated with decreased ZO-1 expression in vivo (Steelant et al., 2018).

However, in AR mice model and AR patients, Th1 cytokines have been associated with increased expression of TJ molecules and decreased AR severity, respectively. Lower levels of Th1 cytokines, IL-2 and IFN- $\gamma$ were detected in the serum sample from OVA-sensitized mice with AR compared with controls (Wang et al., 2016). When the OVA-sensitized mice were treated with SoB, IL-2 and IFN- $\gamma$ levels were increased, leading to increased expression of TJ molecules (Wang et al., 2016). The levels of IFN- $\gamma$ in plasma sample of AR patients was significantly lower compared with healthy controls (Bayrak Degirmenci et al., 2018). The same study showed that downregulated levels of Th1 cytokines were associated with higher severity of AR symptoms. Furthermore, the levels of IFN- $\gamma$ were inversely correlated with higher nasal symptoms scores as measured by evaluating the severity of sneezing, nasal itching, nasal obstruction and watery nasal discharge (Bayrak Degirmenci et al., 2018). Further mechanistic studies are recommended to elucidate whether Th1 cytokines exert their protective effects on nasal epithelial barrier integrity via increased TJ molecules expression in human AR cells.

\section{TH2 CYTOKINES IN AR}

The involvement of Th2 cytokines in AR has been widely investigated. The serum levels of Th2 cytokines including IL-4 and IL-13 are elevated in AR patients (Jordakieva \& Jensen-Jarolim, 2018). Increased expression of IL-4 in nasal epithelial cells of HDM-induced AR patients reduced ZO-1 mRNA expression (Steelant et al., 2016). Breakdown of the epithelial barrier was observed after stimulation of nasal epithelial cells with IL-4 and significantly increased the permeability of FD4 (Steelant et al., 2016). 
309

310

311

312

313

314

315

316

317

318

319

320

321

322

323

324

325

326

327

328

329

330

331

332

333

334

335

336

337

338

339

340

341

342

343

344

345

346

347
Both IL-4 and IL-13 play critical roles in promoting B cells to produce IgE (Shirkani et al., 2019; Zhao et al., 2017). Protein levels of IL-4 and IL-13 in nasal mucosa of guinea pig of ARsensitized pig were higher compared with controls (Zhao et al., 2017). This was supported by findings where higher serum levels of IL-4 and IL-13 were found in AR-sensitized pigs compared with controls (Zhao et al., 2017). In addition, treatment of lung cancer cells (Calu-3) with IL-4 and IL-13 reduced the protein expression of ZO-1 protein (Fukuoka \& Yoshimoto, 2018).

Immunofluorescent staining of human bronchial epithelial cells of asthmatic patients demonstrated that disruption of TJs in the ALI cultures occurred and weak expression of ZO-1 was observed (Wawrzyniak et al., 2017). Blocking IL-4 and IL-13 in asthma patients did not show difference in TER measurement (Srinivasan et al., 2015; Wawrzyniak et al., 2017). However, nullifying the effects of IL-4 and IL-13 using anti-IL4 and anti-IL-13 supplemented to the ALI culture of control bronchial epithelial cells in vitro enhanced the TER measurement (Wawrzyniak et al., 2017). Moreover, IL-4 and IL-13 mRNA expression levels were increased together with downregulated $Z O-1$ mRNA expression in the jejunum of OVA-sensitized rats (Tulyeu et al., 2019).

Downregulation of ZO-1 mRNA expression potentially through regulation by Th2 cytokine was also observed in vivo. Endonasal stimulation of wild-type BALB/c mice with IL-4 and IL-13 demonstrated increased FD4 permeability associated with reduced $Z O-1$ mRNA expression compared with saline-instilled mice (Steelant et al., 2018). Taken together, these studies indicate that IL-4 and IL-13 contribute to the breakdown of nasal epithelial barrier by reducing the expression of $\mathrm{ZO}-1$.

\section{CONCLUSION}

In conclusion, HDAC1 and HDAC2 play pathogenic roles in the breakdown of nasal epithelial barrier integrity via suppression of $\mathrm{ZO}$ proteins expression. This is potentially regulated by $\mathrm{Th} 2$ cytokine signaling pathways as higher levels of Th2 cytokines in AR patients are accompanied with decreased epithelial barrier integrity and ZO-1 expression. In contrast, higher levels of Th1 cytokines appear to preserve the nasal epithelial barrier integrity of AR patients. Future research should investigate and compare which specific HDACi or blocking antibodies of Th2 cytokines that demonstrate potent restoration of $\mathrm{ZO}$ proteins expression in nasal epithelial cells of AR animal models, as well as ameliorating their symptoms. Targeting these pathogenic pathways might be effective in AR therapy to maintain the expression and structure of ZOs at the nasal epithelial barrier. 


\section{REFERENCES}

349

350

351

352

353

354

355

356

357

358

359

360

361

362

363

364

365

366

367

368

369

370

371

372

373

374

375

376

377

378

379

380

381

382

383

384

385

386

387

388

389

390

391

392

393

394

Ackaert C, Kofler S, Horejs-Hoeck J, Zulehner N, Asam C, von Grafenstein S, Fuchs JE, Briza P, Liedl KR, Bohle B, Ferreira F, Brandstetter H, Oostingh GJ, Duschl A. 2014. The impact of nitration on the structure and immunogenicity of the major birch pollen allergen Bet v 1.0101. PLoS One 9:e104520. 10.1371/journal.pone.0104520

Akkoc T, de Koning PJ, Ruckert B, Barlan I, Akdis M, Akdis CA. 2008. Increased activation-induced cell death of high IFN-gamma-producing $T(H) 1$ cells as a mechanism of $\mathrm{T}(\mathrm{H}) 2$ predominance in atopic diseases. J Allergy Clin Immunol 121:652-658 e651. 10.1016/j.jaci.2007.12.1171

Anderson JM. 1996. Cell signalling: MAGUK magic. Curr Biol 6:382-384.

Azid NA, Md Sani M, Zamry AA, Mohd Ashari NS, Tan TH-T, Wong KK, Mohamud R. 2019. Total IgE levels and their relevance in the diagnosis of allergy among Malaysian population in the NorthEast Region of Peninsular Malaysia. 2019 4:7.

Balda MS, Matter K. 2000. The tight junction protein ZO-1 and an interacting transcription factor regulate ErbB-2 expression. EMBO J 19:2024-2033. 10.1093/emboj/19.9.2024

Barnes PJ. 2013. Corticosteroid resistance in patients with asthma and chronic obstructive pulmonary disease. J Allergy Clin Immunol 131:636-645. 10.1016/j.jaci.2012.12.1564

Bauer H, Zweimueller-Mayer J, Steinbacher P, Lametschwandtner A, Bauer HC. 2010. The dual role of zonula occludens (ZO) proteins. J Biomed Biotechnol 2010:402593. 10.1155/2010/402593

Bayrak Degirmenci P, Aksun S, Altin Z, Bilgir F, Arslan IB, Colak H, Ural B, Solakoglu Kahraman D, Diniz G, Ozdemir B, Kirmaz C. 2018. Allergic Rhinitis and Its Relationship with IL-10, IL-17, TGF-beta, IFN-gamma, IL 22, and IL-35. Dis Markers 2018:9131432. 10.1155/2018/9131432

Beutel O, Maraspini R, Pombo-Garcia K, Martin-Lemaitre C, Honigmann A. 2019. Phase Separation of Zonula Occludens Proteins Drives Formation of Tight Junctions. Cell 179:923-936 e911. 10.1016/j.cell.2019.10.011

Bhavsar P, Ahmad T, Adcock IM. 2008. The role of histone deacetylases in asthma and allergic diseases. J Allergy Clin Immunol 121:580-584. 10.1016/j.jaci.2007.12.1156

Bittner S, Ruck T, Schuhmann MK, Herrmann AM, Moha ou Maati H, Bobak N, Gobel K, Langhauser F, Stegner D, Ehling P, Borsotto M, Pape HC, Nieswandt B, Kleinschnitz C, Heurteaux C, Galla HJ, Budde T, WiendI H, Meuth SG. 2013. Endothelial TWIK-related potassium channel-1 (TREK1) regulates immune-cell trafficking into the CNS. Nat Med 19:1161-1165. 10.1038/nm.3303

Bordin M, D'Atri F, Guillemot L, Citi S. 2004. Histone deacetylase inhibitors up-regulate the expression of tight junction proteins. Mol Cancer Res 2:692-701.

Bruewer M, Utech M, Ivanov AI, Hopkins AM, Parkos CA, Nusrat A. 2005. Interferon-gamma induces internalization of epithelial tight junction proteins via a macropinocytosis-like process. FASEB J 19:923-933. 10.1096/fj.04-3260com

Coyne CB, Vanhook MK, Gambling TM, Carson JL, Boucher RC, Johnson LG. 2002. Regulation of airway tight junctions by proinflammatory cytokines. Mol Biol Cell 13:3218-3234. 10.1091/mbc.e02-030134

de Boer WI, Sharma HS, Baelemans SM, Hoogsteden HC, Lambrecht BN, Braunstahl GJ. 2008. Altered expression of epithelial junctional proteins in atopic asthma: possible role in inflammation. Can J Physiol Pharmacol 86:105-112. 10.1139/y08-004

Eifan AO, Durham SR. 2016. Pathogenesis of rhinitis. Clin Exp Allergy 46:1139-1151. 10.1111/cea.12780

Elango S. 2005. Recent trends in the diagnosis and management of allergic rhinitis. Med J Malaysia 60:672-676; quiz 677.

Fukuoka A, Matsushita K, Morikawa T, Takano H, Yoshimoto T. 2016. Diesel exhaust particles exacerbate allergic rhinitis in mice by disrupting the nasal epithelial barrier. Clin Exp Allergy 46:142-152. 10.1111/cea.12597

Peer] reviewing PDF | (2020:01:45164:2:0:NEW 29 Jul 2020) 
401

402

403

404

405

406

407

408

409

410

411

412

413

414

415

416

417

418

419

420

421

422

423

424

425

426

427

428

429

430

431

432

433

434

435

436

437

438

439

440

441

442

Fukuoka A, Yoshimoto T. 2018. Barrier dysfunction in the nasal allergy. Allergol Int 67:18-23. 10.1016/j.alit.2017.10.006

Furuse M, Itoh M, Hirase T, Nagafuchi A, Yonemura S, Tsukita S, Tsukita S. 1994. Direct association of occludin with ZO-1 and its possible involvement in the localization of occludin at tight junctions. J Cell Biol 127:1617-1626.

Ganatra DA, Vasavada AR, Vidya NG, Gajjar DU, Rajkumar S. 2018. Trichostatin A Restores Expression of Adherens and Tight Junction Proteins during Transforming Growth Factor beta-Mediated Epithelial-to-Mesenchymal Transition. J Ophthalmic Vis Res 13:274-283. 10.4103/jovr.jovr_110_17

Gonzalez-Mariscal L, Betanzos A, Avila-Flores A. 2000. MAGUK proteins: structure and role in the tight junction. Semin Cell Dev Biol 11:315-324. 10.1006/scdb.2000.0178

Heinemann U, Schuetz A. 2019. Structural Features of Tight-Junction Proteins. Int J Mol Sci 20. 10.3390/ijms20236020

Herve JC, Derangeon M, Sarrouilhe D, Bourmeyster N. 2014. Influence of the scaffolding protein Zonula Occludens (ZOs) on membrane channels. Biochim Biophys Acta 1838:595-604. 10.1016/j.bbamem.2013.07.006

Jiang J, Liu JQ, Li J, Li M, Chen HB, Yan H, Mo LH, Qiu SQ, Liu ZG, Yang PC. 2015. Trek1 contributes to maintaining nasal epithelial barrier integrity. Sci Rep 5:9191. 10.1038/srep09191

Jordakieva G, Jensen-Jarolim E. 2018. The impact of allergen exposure and specific immunotherapy on circulating blood cells in allergic rhinitis. World Allergy Organ J 11:19. 10.1186/s40413-0180197-0

Kaneko Y, Kohno T, Kakuki T, Takano KI, Ogasawara N, Miyata R, Kikuchi S, Konno T, Ohkuni T, Yajima R, Kakiuchi A, Yokota SI, Himi T, Kojima T. 2017. The role of transcriptional factor p63 in regulation of epithelial barrier and ciliogenesis of human nasal epithelial cells. Sci Rep 7:10935. 10.1038/s41598-017-11481-w

Katzka DA, Tadi R, Smyrk TC, Katarya E, Sharma A, Geno DM, Camilleri M, lyer PG, Alexander JA, Buttar NS. 2014. Effects of topical steroids on tight junction proteins and spongiosis in esophageal epithelia of patients with eosinophilic esophagitis. Clin Gastroenterol Hepatol 12:1824-1829 e1821. 10.1016/j.cgh.2014.02.039

Kojima T, Go M, Takano K, Kurose M, Ohkuni T, Koizumi J, Kamekura R, Ogasawara N, Masaki T, Fuchimoto J, Obata K, Hirakawa S, Nomura K, Keira T, Miyata R, Fujii N, Tsutsumi H, Himi T, Sawada N. 2013. Regulation of tight junctions in upper airway epithelium. Biomed Res Int 2013:947072. 10.1155/2013/947072

Lee HJ, Kim B, Im NR, Lee DY, Kim HK, Lee SH, Lee HM, Lee SH, Baek SK, Kim TH. 2016. Decreased expression of E-cadherin and ZO-1 in the nasal mucosa of patients with allergic rhinitis: Altered regulation of E-cadherin by IL-4, IL-5, and TNF-alpha. Am J Rhinol Allergy 30:173-178. 10.2500/ajra.2016.30.4295

Lee SH. 2015. Intestinal permeability regulation by tight junction: implication on inflammatory bowel diseases. Intest Res 13:11-18. 10.5217/ir.2015.13.1.11

Lei W, Zhang K, Pan X, Hu Y, Wang D, Yuan X, Shu G, Song J. 2010. Histone deacetylase 1 is required for transforming growth factor-beta1-induced epithelial-mesenchymal transition. Int J Biochem Cell Biol 42:1489-1497. 10.1016/j.biocel.2010.05.006

London NR, Jr., Ramanathan M, Jr. 2017. The Role of the Sinonasal Epithelium in Allergic Rhinitis. Otolaryngol Clin North Am 50:1043-1050. 10.1016/j.otc.2017.08.002

Marshall JS, Warrington R, Watson W, Kim HL. 2018. An introduction to immunology and immunopathology. Allergy Asthma Clin Immunol 14:49. 10.1186/s13223-018-0278-1

Pang KA, Pang KP, Pang EB, Tan YN, Chan YH, Siow JK. 2017. Food allergy and allergic rhinitis in 435 asian patients - A descriptive review. Med J Malaysia 72:215-220. 
Rescigno M, Urbano M, Valzasina B, Francolini M, Rotta G, Bonasio R, Granucci F, Kraehenbuhl JP, Ricciardi-Castagnoli P. 2001. Dendritic cells express tight junction proteins and penetrate gut epithelial monolayers to sample bacteria. Nat Immunol 2:361-367. 10.1038/86373

Roehlen N, Roca Suarez AA, El Saghire H, Saviano A, Schuster C, Lupberger J, Baumert TF. 2020. Tight Junction Proteins and the Biology of Hepatobiliary Disease. Int J Mol Sci 21. 10.3390/ijms21030825

Runswick S, Mitchell T, Davies P, Robinson C, Garrod DR. 2007. Pollen proteolytic enzymes degrade tight junctions. Respirology 12:834-842. 10.1111/j.1440-1843.2007.01175.x

Sani MM, Ashari NSM, Abdullah B, Wong KK, Musa KI, Mohamud R, Tan HT. 2019. Reduced CD4+ terminally differentiated effector memory $T$ cells in moderate-severe house dust mites sensitized allergic rhinitis patients. Asian Pac J Allergy Immunol 37:138-146. 10.12932/AP191217-0220

Sankaran P, Brockwell C, Clark A, Wilson A. 2014. P232 Treatment Of Allergic Rhinitis With Theophylline : A Double-blind, Randomised, Crossover Study. Thorax 69:A179-A179. 10.1136/thoraxjnl-2014206260.360

Sarin S, Undem B, Sanico A, Togias A. 2006. The role of the nervous system in rhinitis. J Allergy Clin Immunol 118:999-1016. 10.1016/j.jaci.2006.09.013

Schleimer RP, Berdnikovs S. 2017. Etiology of epithelial barrier dysfunction in patients with type 2 inflammatory diseases. J Allergy Clin Immunol 139:1752-1761. 10.1016/j.jaci.2017.04.010

Shakespear MR, Halili MA, Irvine KM, Fairlie DP, Sweet MJ. 2011. Histone deacetylases as regulators of inflammation and immunity. Trends Immunol 32:335-343. 10.1016/j.it.2011.04.001

Shirasaki H, Kanaizumi E, Seki N, Himi T. 2011. Correlation of Local FOXP3-Expressing T Cells and Th1Th2 Balance in Perennial Allergic Nasal Mucosa. Int J Otolaryngol 2011:259867. $10.1155 / 2011 / 259867$

Shirkani A, Mansouri A, Farid Hosseini R, Jabbari Azad F, Alsadat Mahmoudian R, Montazer M, Samimi A, Momtazi-Borojeni AA, Abbaszadegan MR, Gholamin M. 2019. The Role of Interleukin-4 and 13 Gene Polymorphisms in Allergic Rhinitis: A Case Control Study. Rep Biochem Mol Biol 8:111118.

Sin B, Togias A. 2011. Pathophysiology of allergic and nonallergic rhinitis. Proc Am Thorac Soc 8:106-114. 10.1513/pats.201008-057RN

Soyka MB, Wawrzyniak P, Eiwegger T, Holzmann D, Treis A, Wanke K, Kast Jl, Akdis CA. 2012. Defective epithelial barrier in chronic rhinosinusitis: the regulation of tight junctions by IFNgamma and IL-4. J Allergy Clin Immunol 130:1087-1096 e1010. 10.1016/j.jaci.2012.05.052

Srinivasan B, Kolli AR, Esch MB, Abaci HE, Shuler ML, Hickman JJ. 2015. TEER measurement techniques for in vitro barrier model systems. J Lab Autom 20:107-126. 10.1177/2211068214561025

Steelant B, Farre R, Wawrzyniak P, Belmans J, Dekimpe E, Vanheel H, Van Gerven L, Kortekaas Krohn I, Bullens DMA, Ceuppens JL, Akdis CA, Boeckxstaens G, Seys SF, Hellings PW. 2016. Impaired barrier function in patients with house dust mite-induced allergic rhinitis is accompanied by decreased occludin and zonula occludens-1 expression. J Allergy Clin Immunol 137:1043-1053 e1045. 10.1016/j.jaci.2015.10.050

Steelant B, Seys SF, Van Gerven L, Van Woensel M, Farre R, Wawrzyniak P, Kortekaas Krohn I, Bullens DM, Talavera K, Raap U, Boon L, Akdis CA, Boeckxstaens G, Ceuppens JL, Hellings PW. 2018. Histamine and Thelper cytokine-driven epithelial barrier dysfunction in allergic rhinitis. J Allergy Clin Immunol 141:951-963 e958. 10.1016/j.jaci.2017.08.039

Steelant B, Wawrzyniak P, Martens K, Jonckheere AC, Pugin B, Schrijvers R, Bullens DM, Vanoirbeek JA, Krawczyk K, Dreher A, Akdis CA, Hellings PW. 2019. Blocking histone deacetylase activity as a novel target for epithelial barrier defects in patients with allergic rhinitis. J Allergy Clin Immunol 144:1242-1253 e1247. 10.1016/j.jaci.2019.04.027

Peer) reviewing PDF | (2020:01:45164:2:0:NEW 29 Jul 2020) 
491

492

493

494

495

496

497

498

499

500

501

502

503

504

505

506

507

508

509

510

511

512

513

514

515

516

517

518

519

520

521

522

523

524

525

526

527

528

529

530

531

532

533

534

535

536
Sun R, Yang Y, Huo Q, Gu Z, Wei P, Tang X. 2020. Increased expression of type 2 innate lymphoid cells in pediatric patients with allergic rhinitis. Exp Ther Med 19:735-740. 10.3892/etm.2019.8235

Sung SS, Fu SM, Rose CE, Jr., Gaskin F, Ju ST, Beaty SR. 2006. A major lung CD103 (alphaE)-beta7 integrin-positive epithelial dendritic cell population expressing Langerin and tight junction proteins. J Immunol 176:2161-2172.

Sweet MJ, Shakespear MR, Kamal NA, Fairlie DP. 2012. HDAC inhibitors: modulating leukocyte differentiation, survival, proliferation and inflammation. Immunol Cell Biol 90:14-22. 10.1038/icb.2011.88

Tanno LK, Calderon MA, Smith HE, Sanchez-Borges M, Sheikh A, Demoly P, Joint Allergy A. 2016. Dissemination of definitions and concepts of allergic and hypersensitivity conditions. World Allergy Organ J 9:24. 10.1186/s40413-016-0115-2

Tulyeu J, Kumagai H, Jimbo E, Watanabe S, Yokoyama K, Cui L, Osaka H, Mieno M, Yamagata T. 2019. Probiotics Prevents Sensitization to Oral Antigen and Subsequent Increases in Intestinal Tight Junction Permeability in Juvenile-Young Adult Rats. Microorganisms 7. 10.3390/microorganisms7100463

Turgeon N, Blais M, Gagne JM, Tardif V, Boudreau F, Perreault N, Asselin C. 2013. HDAC1 and HDAC2 restrain the intestinal inflammatory response by regulating intestinal epithelial cell differentiation. PLoS One 8:e73785. 10.1371/journal.pone.0073785

Umeda K, Ikenouchi J, Katahira-Tayama S, Furuse K, Sasaki H, Nakayama M, Matsui T, Tsukita S, Furuse M, Tsukita S. 2006. ZO-1 and ZO-2 independently determine where claudins are polymerized in tight-junction strand formation. Cell 126:741-754. 10.1016/j.cell.2006.06.043

Vendetti FP, Rudin CM. 2013. Epigenetic therapy in non-small-cell lung cancer: targeting DNA methyltransferases and histone deacetylases. Expert Opin Biol Ther 13:1273-1285. 10.1517/14712598.2013.819337

Wan H, Winton HL, Soeller C, Tovey ER, Gruenert DC, Thompson PJ, Stewart GA, Taylor GW, Garrod DR, Cannell MB, Robinson C. 1999. Der $p 1$ facilitates transepithelial allergen delivery by disruption of tight junctions. J Clin Invest 104:123-133. 10.1172/JCI5844

Wang J, Wen L, Wang Y, Chen F. 2016. Therapeutic Effect of Histone Deacetylase Inhibitor, Sodium Butyrate, on Allergic Rhinitis In Vivo. DNA Cell Biol 35:203-208. 10.1089/dna.2015.3037

Wang Y, Chen H, Chen Q, Jiao F-Z, Zhang W-B, Gong Z-J. 2018. The Protective Mechanism of CAY10683 on Intestinal Mucosal Barrier in Acute Liver Failure through LPS/TLR4/MyD88 Pathway. Mediators of Inflammation 2018:11. 10.1155/2018/7859601

Wang Y, Lv L, Zang H, Gao Z, Zhang F, Wang X, Zhou X. 2015. Regulation of Trek1 expression in nasal mucosa with allergic rhinitis by specific immunotherapy. Cell Biochem Funct 33:23-28. 10.1002/cbf.3075

Wawrzyniak P, Wawrzyniak M, Wanke K, Sokolowska M, Bendelja K, Ruckert B, Globinska A, Jakiela B, Kast JI, Idzko M, Akdis M, Sanak M, Akdis CA. 2017. Regulation of bronchial epithelial barrier integrity by type 2 cytokines and histone deacetylases in asthmatic patients. J Allergy Clin Immunol 139:93-103. 10.1016/j.jaci.2016.03.050

Wheatley LM, Togias A. 2015. Clinical practice. Allergic rhinitis. N Engl J Med 372:456-463. 10.1056/NEJMcp1412282

Zhang N, Van Crombruggen K, Gevaert E, Bachert C. 2016. Barrier function of the nasal mucosa in health and type-2 biased airway diseases. Allergy 71:295-307. 10.1111/all.12809

Zhao C, Yu S, Li J, Xu W, Ge R. 2017. Changes in IL-4 and IL-13 expression in allergic-rhinitis treated with hydrogen-rich saline in guinea-pig model. Allergol Immunopathol (Madr) 45:350-355. 10.1016/j.aller.2016.10.007

PeerJ reviewing PDF | (2020:01:45164:2:0:NEW 29 Jul 2020) 
537 Zhou H, Wang J, Peng G, Song Y, Zhang C. 2015. A novel treatment strategy in hepatocellular carcinoma

538

539

540

541

542 Figure Legends

543 Figure 1: Pathophysiology of allergic rhinitis (AR) involving the disruption of nasal 544 epithelial barrier and regulation by HDACs, Th1 and Th2 cytokines. 


\section{Table $\mathbf{1}$ (on next page)}

Table 1: The expression of Zonula Occludens (ZOs) in human and animal models 
Table 1: The expression of Zonula Occludens (ZOs) in human and animal models

\begin{tabular}{|c|c|c|c|c|}
\hline ZOs & Samples & Treatment & $\begin{array}{l}\text { Change in } \\
\text { expression }\end{array}$ & References \\
\hline \multirow[t]{13}{*}{ ZO-1 } & \multicolumn{4}{|c|}{ Treatment with Th1 cytokines: } \\
\hline & $\begin{array}{l}\text { Nasal mucosa from } \\
\text { normal wild type } \\
\text { BALB/c mice }\end{array}$ & TNF- $\alpha$, IFN- $\gamma$ & Downregulated & $\begin{array}{l}\text { (Steelant et } \\
\text { al., 2018) }\end{array}$ \\
\hline & $\begin{array}{l}\text { Nasal epithelial cells } \\
\text { from HDM-induced } \\
\text { AR patients }\end{array}$ & IFN- $\gamma$ & Downregulated & $\begin{array}{l}\text { (Steelant et } \\
\text { al., 2016) }\end{array}$ \\
\hline & \multicolumn{4}{|c|}{ Treatment with Th2 cytokines: } \\
\hline & $\begin{array}{l}\text { Nasal mucosa from } \\
\text { normal wild type } \\
\text { BALB/c mice }\end{array}$ & IL-4 & Downregulated & $\begin{array}{l}\text { (Steelant et } \\
\text { al., 2018) }\end{array}$ \\
\hline & $\begin{array}{l}\text { Nasal epithelial cells } \\
\text { from HDM-induced } \\
\text { AR patients }\end{array}$ & IL-4 & Downregulated & $\begin{array}{l}\text { (Steelant et } \\
\text { al., 2016) }\end{array}$ \\
\hline & $\begin{array}{l}\text { Calu-3 cells (human } \\
\text { epithelial nasal cell } \\
\text { lines) }\end{array}$ & IL-4 and IL-13 & Downregulated & $\begin{array}{l}\text { (Fukuoka \& } \\
\text { Yoshimoto, } \\
\text { 2018) }\end{array}$ \\
\hline & \multicolumn{4}{|l|}{ Other treatment: } \\
\hline & $\begin{array}{l}\text { Human nasal epithelial } \\
\text { cell line, RPMI } 2650\end{array}$ & $\begin{array}{l}\text { Cultured with diesel } \\
\text { exhaust particle } \\
\text { (DEP) }\end{array}$ & Downregulated & $\begin{array}{l}\text { (Fukuoka et } \\
\text { al., 2016) }\end{array}$ \\
\hline & $\begin{array}{l}\text { Nasal epithelial cells } \\
\text { in AR mice }\end{array}$ & $\begin{array}{l}\text { Intranasal } \\
\text { administration with } \\
\text { DEP }\end{array}$ & Downregulated & $\begin{array}{l}\text { (Fukuoka et } \\
\text { al., 2016) }\end{array}$ \\
\hline & $\begin{array}{l}\text { Nasal biopsy } \\
\text { specimens from HDM- } \\
\text { induced AR patients }\end{array}$ & No treatment & Downregulated & $\begin{array}{l}\text { (Steelant et } \\
\text { al., 2016) }\end{array}$ \\
\hline & $\begin{array}{l}\text { Bronchial epithelium } \\
\text { biopsy from asthmatic } \\
\text { patients }\end{array}$ & No treatment & Downregulated & $\begin{array}{l}\text { (de Boer et } \\
\text { al., 2008) }\end{array}$ \\
\hline & $\begin{array}{l}\text { Nasal epithelial cells } \\
\text { from septal surgery } \\
\text { patients }\end{array}$ & $\begin{array}{l}\text { Treated with } \\
\text { Alternaria alternate }\end{array}$ & Downregulated & $\begin{array}{l}\text { (Shin et al., } \\
\text { 2019) }\end{array}$ \\
\hline ZO-2 & $\begin{array}{l}\text { Nasal biopsy } \\
\text { specimens from } \\
\text { chronic rhinosinusitis }\end{array}$ & No treatment & Downregulated & $\begin{array}{l}\text { (Soyka et al., } \\
\text { 2012) }\end{array}$ \\
\hline
\end{tabular}




\begin{tabular}{|l|l|l|l|l|}
\hline & patients & & & \\
\hline ZO-3 & $\begin{array}{l}\text { Esophageal epithelia } \\
\text { biopsy samples from } \\
\text { patient with } \\
\text { eosinophilic } \\
\text { esophagitis (EoE) }\end{array}$ & $\begin{array}{l}\text { Treated topical } \\
\text { fluticasone }\end{array}$ & Upregulated & $\begin{array}{l}\text { (Katzka et } \\
\text { al., 2014) }\end{array}$ \\
\cline { 2 - 5 } & $\begin{array}{l}\text { Esophageal epithelia } \\
\text { biopsy samples from } \\
\text { patient with EoE }\end{array}$ & No treatment & Downregulated & $\begin{array}{l}\text { (Katzka et } \\
\text { al., 2014) }\end{array}$ \\
\hline
\end{tabular}

2 
Figure 1

Figure 1: Pathophysiology of allergic rhinitis (AR) from the disruption of nasal epithelial barrier and the involvement of HDACs, Th1 and Th2 cytokines.

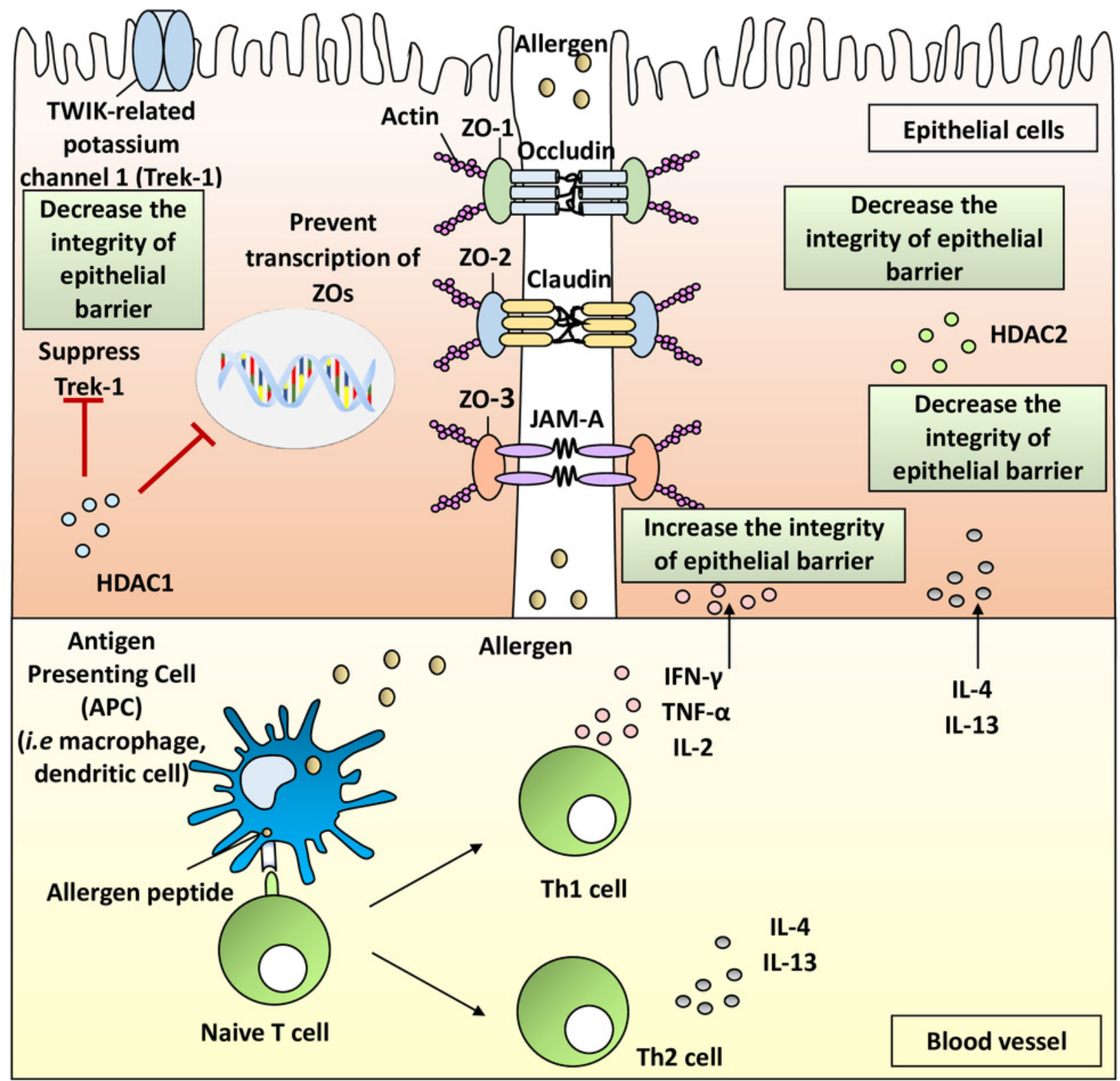

